\title{
Notas sobre o Ensino de Filosofia na Pós-Modernidade ${ }^{i}$
}

Ingrid Müller Xavier ${ }^{\mathrm{ii}}$

“[...] que a filosofia não é produtiva é muito evidente a partir dos primeiros que filosofaram. Pois os homens tanto agora como outrora, começaram a filosofar devido ao assombro”. Aristóteles, Metafísica 982 b 11

Este trabalho tem por objetivo examinar possíveis contribuições de Lyotard e Jameson para pensar um dos obstáculos ao ensino de filosofia que, por falta de melhor denominação chamaremos “regime de atenção dos adolescentes contemporâneos”.

Uma vez que em agosto de 2006 foram, finalmente, introduzidas a sociologia e a filosofia como disciplinas obrigatórias no currículo do Ensino Médio ${ }^{\mathrm{iii}}$, pensamos ser relevante propormonos a explorar algumas das dificuldades com as quais os professores se enfrentam. Pretendemos apontar alguns problemas e compartilhar algumas perguntas que vêm surgindo na nossa prática docente. Em um primeiro momento consideramos como a experiência contemporânea da temporalidade apontada por Jameson repercute no ensino de filosofia, tentando vincular esta questão à noção de uma "estética do mapeamento cognitivo" por ele proposta. Em seguida esboçaremos algumas reflexões em torno do significado que o apagamento do papel do professor e a exigência pós-moderna, indicados por Lyotard, de traduzir o conhecimento em linguagem de máquina, pode ter para o ensino de filosofia.

I. Notas sobre a pós-modernidade

“O saber muda de estatuto ao mesmo tempo que as sociedades entram na idade dita pós-industrial e as culturas na idade dita pós-moderna.”

(Lyotard ,2006, p. 5).

Números 8/9: Maio/2007 - abril/2008 
Em A condição pós-moderna Lyotard define o termo pós-moderno como sendo o “[...] estado da cultura após as transformações que afetaram as regras dos jogos das ciências, da literatura e das artes a partir do final do século XIX.” (2006, p. 15). Portanto, mais que uma periodização ou a delimitação de uma época histórica, o que o pensador caracteriza como próprio à condição pós-moderna é um estado particular da cultura em que as relações entre saber e poder ganham outras determinações. A análise de Lyotard o leva a entender a transformação que os saberes das sociedades do centro do capitalismo experimentaram: a informatização. Saber em franco contraste face àquele saber iluminista. O fato de que a ciência contemporânea esteja sendo atravessada por critérios eminentemente técnicos repercute necessariamente sobre o critério de verdade. Lyotard, seguindo a análise do controle da verdade, de como a entende Fouconnier, dirá:

[...] Assim toma forma a legitimação pelo poder. Este não é somente o bom desempenho, mas também a boa verificação e o bom veredicto. $\mathrm{O}$ poder legitima a ciência e o direito por sua eficiência, e esta por aqueles. Ele se autolegitima como parece fazê-lo um sistema regulado sobre a otimização de suas performances. ”(2006, p. 84).

A legitimação do conhecimento se assenta em um poder de desempenho. Tornado uma mercadoria, um veículo técnico de intercâmbio, de comunicação, de informação e de tradução, parece não mais haver conexões possíveis entre o saber e as esferas da ética, da política e da estética tal como fora proposto na modernidade ilustrada. A crise do saber teria sua origem na erosão interna do seu próprio princípio de legitimidade: a performatividade. Essa lógica do “melhor desempenho” atropela um sem fim de questões, sejam estas de natureza ética, filosófica ou mesmo religiosa, deixando a condução das deliberações a cargo de uma classe dirigente, a que Lyotard chama de “decisores”, constituída predominantemente por empresários, altos funcionários e políticos e que exclui, não só a intelectualidade acadêmica, mas também a sociedade como um todo. O incremento de poder e sua autolegitimação se sustentam, agora, na produção, memorização, acessibilidade e operacionalidade e, o objetivo final, é a otimização ou o aumento de output das informações geradas e diminuição de input da energia investida para gerar as informações. A transformação operada no conhecimento exige sua tradutibilidade em quantidades de informação, submetida à hegemonia da informática e sua lógica própria, a saber, seus resultados devem ser passíveis de tradução em linguagem de máquina. Se até o advento da pós-modernidade houve um vínculo entre saber e formação do espírito, uma vez desfeito esse elo, 
a questão da formação do espírito perde vigência. O saber, posto no mesmo plano que a mercadoria, perde seu valor de uso e passa a ser produzido para ter o mesmo destino da mercadoria: a comercialização. O saber adquire o estatuto de mercadoria informacional, vindo a ser um dos mais importantes artigos na disputa pelo poder. O liame saber-poder-política e governo ganha uma dimensão até então desconhecida e passa a operar segundo os ditames da lógica empresarial. Lyotard afirma expressamente que, diante dessas exigências da cultura pósmoderna “[...] a deslegitimação e a prevalência do critério de desempenho soam como a hora final da era do Professor: ele não é mais competente que as redes de memória para transmitir o saber estabelecido” (2006, p. 95-96).

Esta questão será retomada em meio a algumas notas sobre o ensino de filosofia onde se discute a copertinência Filosofia-ensino e o papel do professor. Traremos agora breves aportes do pensamento de Jameson para situarmo-nos, também com ele, na compreensão do que possa ser a pós-modernidade. “O pós-modernismo é o consumo da própria produção de mercadorias como processo” (Jameson, 1997, p. 14). À diferença de Lyotard, quem vincula a pós-modernidade ao fim das narrativas mestras, Jameson, que inclusive põe em questão o próprio conceito de pósmoderno (1997, p. 25), não o vê como a instauração de uma tendência absolutamente nova, não seria um tempo singular que apresentasse uma descontinuidade radical com a modernidade que lhe antecedeu e que pudesse configurar de maneira inequívoca a ordem social de uma época, mas tão somente um reflexo “[...] de mais uma modificação sistêmica do próprio capitalismo" (Jameson, 1997, p. 15-16). Para Jameson, o tema e mesmo a expressão ‘pós-moderno’ e sua penetração nas diversas esferas do cotidiano, de modo talvez leviano e banalizado, tem o perigo de desviar a nossa atenção do âmbito da economia, que é de fato o que o autor privilegia como sendo suficientemente significativo para figurar como subtítulo da obra que estamos a examinar.

Uma das teses centrais do pensamento de Jameson nesta obra (1997, p. 25ss) é a fusão do cultural e o econômico de modo a significarem a mesma coisa e o conseqüente apagamento da fronteira entre alta cultura e cultura de massa, já que também a produção estética obedece à lógica da produção das mercadorias. O autor defende que o pós-modernismo é uma “dominante cultural” de ação globalizante que exprime uma “[...] nova era de dominação, militar e econômica dos Estados Unidos sobre o resto do mundo.” (1997, p. 31). Um outro aspecto dessa dominante cultural que Jameson aponta e que vemos ressoar na educação é o ‘esmaecimento dos afetos’ e o 'esmaecimento do tempo e da temporalidade'. Em especial nos parece interessar à pedagogia a 
sua avaliação de que, em uma cultura cada vez mais dominada pela lógica espacial, têm lugar significativas transformações sobre a experiência do tempo e da temporalidade e, conseqüentemente, na subjetividade. "O sujeito perdeu sua capacidade de estender de forma ativa suas protensões e retensões em um complexo temporal e organizar seu passado e seu futuro como uma experiência coerente.” (Jameson,1997, p. 52). Jameson aponta a necessidade de se pensar a noção, ainda incipiente, e que nos convida a inventar, de uma "estética do mapeamento cognitivo” (1997, p. 79), ao indicar que uma cultura política e pedagógica precisa conferir ao sujeito individual uma melhor apreciação de seu lugar no sistema global. Cremos que Paul Virilio, Felix Guattari e Jonathan Crary, ao nos ajudarem a pensar alguns efeitos dos processos midiáticos contemporâneos sobre as rítmicas perceptiva e cognitiva, podem com isso contribuir para o esboço de uma "estética do mapeamento cognitivo”.

II. Notas sobre ensino de filosofia e o sujeito da educação

“A filosofia não se ensina. Pode-se ensinar uma técnica, que permita, no máximo, trabalhar como filósofo, fazer filosofia, mas a filosofia mesma não é algo que já exista dada e que se ensine... Platão não é simplesmente seus Diálogos. Era um homem que falava diante de outros. Isso se perdeu, isso era filosofia...”.

J.P. Sartre

O ensino de filosofia tem uma longa história. A Sócrates é atribuída a condição de ter sido o primeiro professor de filosofia. Estranho professor... Não lecionava em escolas, não dava aulas regulares, não escrevia livros, não cobrava pelos seus ensinamentos, nem tampouco se considerava professor.

Durante seu julgamento, segundo o relato que nos deixou Platão em Apologia de Sócrates, ante as acusações de seus adversários, Sócrates teria assim respondido: "Eu nunca fui mestre de ninguém, conquanto nunca me opusesse a moço ou velho que me quisesse ouvir no 
desempenho de minha tarefa” (Platão, 1987, 33a-33b). Vinte e cinco séculos nos separam do patrono da filosofia e, desde então escolas, currículos, horários e alunos transformaram por inteiro a relação da filosofia com o aprender e o ensinar. Se Sócrates desempenhava, o que ele chamava de missão, tendo por alunos aqueles que o elegiam como mestre, há muito, os alunos têm por mestres aqueles que lhes cabem, a depender da escola em que foram matriculados por seus responsáveis. O aprender, desde a obrigatoriedade da escolarização, distanciou-se cada vez mais de uma escolha pessoal para se converter em uma norma geral. O que visava Sócrates? Certamente não apenas a aquisição de conhecimento, caso entendermos conhecimento como uma técnica que permite a verificação de um objeto qualquer, ou seja, a aquisição de qualquer procedimento que possibilite a descrição, o cálculo ou a previsão controlável de uma entidade, fato ou coisa. (Abbagnano, 1982, p. 160). Mais que relacionar a filosofia ao conhecimento de objetos, a proposta socrática situa o ato filosófico no âmbito do si e do ser. Filosofar teria por objetivo principal uma conversão que, ao transformar a vida de cada um, nos levaria à mudança do próprio modo de ser e viver, permitindo passar de um estilo de vida amodorrado obscurecido pelos imperativos externos de adequação ao já previamente determinado - a um viver mais autêntico já que mais preocupado com a transformação de si mesmo do que com a adaptabilidade. Mais que construção teórica a filosofia seria uma prática que tem por meta 'dar conta de si’. Assim compreendida, a filosofia estaria voltada à inquietude de si, ao propor que cada um faça de sua própria vida um teatro de experiências. Em que cenário nos encontramos hoje os professores de filosofia?

Aceitando o convite de Jameson quanto à necessidade de pensar uma "estética do mapeamento cognitivo”, tomaremos como ponto de partida uma perspectiva do cenário atual em que se desenvolve a atividade docente. Cremos que avaliar esse cenário implica atentar para o papel da mídia e seus dispositivos de antropotécnica no horizonte da cultura da visualidade e do espetáculo. Utilizamos o termo antropotécnica para fazer referência a diversos processos de subjetivação. O que se pretende aquilatar é em que medida as transformações nos processos de percepção, cognição e socialização, operadas pela imagem televisiva e seu rápido fluir, interferem na organização do corpo social, do corpo individual e no sentido da historicidade. Segundo Jonathan Crary (2001, p. 71), a televisão é o meio mais penetrante e eficiente de controle da atenção. Uma vez que a atenção é um âmbito estratégico para o controle social, a televisão como um meio que está entrelaçado à vida social e subjetiva emerge como um poderoso 
modo de produção da subjetividade contemporânea. Tentaremos aqui abordar alguns efeitos do impacto do fluxo de imagem midiático nas rítmicas perceptiva e cognitiva. Interessa-nos, portanto, destacar não o conteúdo das imagens, mas sua ação psicofísica, independentemente do conteúdo imagético. O fluxo de imagens, instrumento e alicerce das novas tecnologias dos meios de comunicação de massa, em especial da televisão, participa significativamente na constituição, manejo e controle da subjetividade ao afetar a experiência da temporalidade e unicidade do sujeito. Estamos convencidos de que o “regime de atenção dos adolescentes contemporâneos” se vê assim refém de uma nova experiência de fragmentação da atenção que Guatttari descreve:

borders on the hypnotic 2) of a captive relation with the narrative content of the program, associated with a lateral awareness of surrounding events - water boiling on the stove, a child's cry, the telephone...3) of a world of phantasms occupying my daydreams. My feeling of personal identity is thus pulled in different directions. How can I maintain a relative sense of unity, despite the diversity of components of subjectivation that pass through me? ? $^{\text {iv }}$

A atenção, melhor dizendo a atentividade (attentiveness) é uma experiência subjetiva intimamente vinculada à temporalidade. Um dos vetores fundamentais na organização do fluxo de imagens é a velocidade. A velocidade vertiginosa com que as imagens são transmitidas, e até justapostas, interfere nas rítmicas perceptiva e cognitiva de modo a determinar no espectador uma deformação da experiência da temporalidade. Isto porque o regime de temporalidade promovido pelo fluxo das imagens televisiva é o do incessante agora. A velocidade se reveste então de um caráter antropofágico, uma vez que é capaz de devorar e perverter os perfis das rítmicas perceptiva e cognitiva. A velocidade imagética é, pois, um dispositivo antropotécnico. Paul Virilio denomina “tempo luz” àquele em que a duração intensiva do instante "real” predomina sobre a duração do tempo extensivo da história, que engloba presente, passado e futuro.

Focalizar, polarizar a atenção de cada um é reorganizar progressivamente o regime de temporalidade das populações (...). A imagem direta é um filtro, não pelo espaço, pelo enquadramento da tela, mas, antes de mais nada, por sua temporalidade: um filtro monocrônico que só deixa passar o presente. (...) estamos diante de uma técnica videocóspica, de uma 
logística da percepção necessária à aquisição progressiva dos alvos nervosos que nos tornamos.”v

Tornamo-nos “alvos nervosos”. Seres eletromagnéticos atravessados por imagens, viventes da imediatez. A imediatez da imagem, ao priorizar o agora em detrimento do antes e do depois, produz, simultaneamente, à guisa de propriedade emergente, consideráveis efeitos sobre rítmica percepto-cognitiva, na medida em que induz a um sistema de estímulo e resposta, cuja demanda por respostas cada vez mais céleres, abole o tempo da hesitação. É aí que intervém o tropel do fluxo de imagem atropelando a hesitação. Se for certo que pensar exige hesitação, então a imediatez da imagem, que suscita e requer reflexos e reações também imediatos, ao preterir a reflexão, provoca uma transformação inaudita de despotencialização do pensamento. A onipresença da imagem midiática monocrônica ordena uma percepção desenquadrada do tempo ao configurar a percepção segundo uma temporalidade determinada: o tempo da imagem midiática é o agora. A análise dos diferentes modos como a aceleração -presidindo uma política econômica da velocidade própria ao capitalismo “turbinado" -incide sobre a subjetividade é objeto de investigação de Virilio levando-o a formular o conceito de "amputação do volume do tempo” (2000, p. 43). A inserção do homem no tempo cronológico, experimentado desde o corpo-próprio, é de natureza tridimensional: passado, presente e futuro. Essa tríplice dimensão permite compreender o tempo como volume, a experiência do tempo é, pois, volumétrica. A imagem midiática, ao enfatizar a dimensão do presente, determina que cada vez mais se viva em um “tempo real”, cuja imediaticidade tem primazia absoluta sobre o futuro e o passado. A globalização apodera-se também do tempo. A empresa Swatch criou o webwatch, que funciona segundo uma nova marcação do tempo, o internet time ou tempo global. As 24 horas de um dia foram divididas em 1000 swatch beats (@1000). Cada uma destas unidades equivale a 1 minuto e 26,4 segundos, de modo que @760 representa 16h31 em Lisboa e 22h31 em Calcutá. ${ }^{\text {vi }}$ O mundo inteiro pode ser agora regulado por um só fuso horário. Time is money, adágio da política da velocidade, concentra bem que na cultura tecnológica do dinheiro o poder se exerce como, no, sobre e desde o tempo. O “instante telepresente”, falseado por sua própria imediatez, não é mais o tempo do corpo-próprio cotidiano. A desterritorialização provocada pela era high tech efetua transformações profundas na relação do homem com o tempo. Desterritorialização que resulta do fato de que o espaço da espectação televisiva, além de compactar o tempo, institui-se a si próprio como espaço que abole as distâncias. A sociedade contemporânea videota vive subordinada a 
uma política da velocidade que prescreve o eterno presente. Esta modalidade de espaço-tempo tecnológico promove a retração do aqui do corpo-próprio, em que vige a experiência de passado, futuro e presente e, ao emancipá-lo da imersão em sua imanência, o encerra em um eterno agora, amputando o volume do tempo e comprometendo as rítmicas perceptiva e cognitiva. "Deste modo, o desenvolvimento de altas velocidades técnicas terá como resultado o desaparecimento da consciência enquanto percepção direta dos fenômenos que nos informam sobre nossa própria existência” (Virilio, 1988, P. 120).

Segundo Virilio, a tirania do tempo real compromete significativamente a experiência do pensamento. Ao não divergir em muito da tirania clássica, a tirania do tempo real, tirania do presente incessante, desenquadra o homem da tridimensionalidade temporal, transformando a todos em espectadores e desta forma substituindo o esforço de reflexão pela passividade do reflexo, é aí, bem mais que no conteúdo por vezes violento da imagem midiática facilmente evidenciável, que reside à violência sub-reptícia da televisão. Portanto, a imagem televisiva encarna a violência não apenas por veicular imagens de cenas violentas ou por fazer às vezes do real sobrepondo-se a ele e ficcionalizando-o, mas sobretudo "[...] por oferecer um suposto gozo imediato do telespectador e, com isso impedir os processos psíquicos e sociais de simbolização sem os quais o desejo não pode efetuar-se, isto é, a dúvida, a reflexão, a crítica, o diálogo encontram-se totalmente bloqueados” (Chaú́, 2004, p. 11). Conseqüência na esfera cognitiva do efeito produzido pela onipresença da imagem é o empobrecimento do universo locucional que se reduz à linguagem estereotipada e facilmente reconhecível. Uma vez que o discurso televisivo se dirige indistintamente a todos, sua linguagem, simplificada e simplificadora, não enseja que o público espectador constitua um universo simbólico abstrato-formal mais complexo. Alain Badiou, por entender a filosofia como uma revolta do pensamento, vinculada à critica e à resistência em relação ao já dado, afirma que nosso mundo pós-moderno “[...] não quer e não gosta da filosofia” (2002, p. 13). Nosso mundo é avesso à filosofia, uma vez que pede a todos que nos adaptemos. Podemos dar assentimento a essa afirmação quando lemos que alguns projetos políticos pedagógicos das nossas escolas enfatizam a necessidade de promover uma educação que viabilize a "flexibilidade adaptativa", ou seja, educar vem sendo entendido como disponibilizar competências e habilidades para que os jovens possam se adaptar de maneira adequada a um mundo em frenética mudança. Badiou aponta também outro componente da filosofia: a lógica e o desejo de uma razão coerente, no entanto... 
Nosso mundo não gosta da lógica (...) Ele está submetido à comunicação, às imagens. Ora, o mundo das imagens, o mundo da mídia, é instantâneo e incoerente. É um mundo rápido e sem memória (...) Sustentar firmemente uma lógica do pensamento é, portanto, muito difícil.” (2002, p. 13).

Se acompanharmos o pressuposto socrático de que filosofia, mais que teoria, é uma prática de si mesmo, como ajustá-la ao imperativo da eficiência? Como ensinar uma disciplina que não se deixa reduzir à linguagem da máquina? Como trabalhar uma disciplina que requer atenção a longas cadeias argumentativas, se estamos diante de um crescente nomadismo e flutuação da atenção? As exigências de produtividade e eficiência tão caras à pós-modernidade estão muito distantes das pretensões da filosofia, que não se arvora a produzir nada, tampouco nada tem a ver com a eficiência, enquanto rendimento e operatividade. Se algo pode a filosofia é nos ajudar a gerar. Gerar inquietude e signos, desinstalar-nos, gerar um outro "nós”. Gerar em nós experiências de transformação. É aí que pode intervir o mestre e por isso é preocupante a afirmação de Lyotard antes citada e que retomamos aqui: “a deslegitimação e a prevalência do critério de desempenho soam como a hora final da era do Professor: ele não é mais competente que as redes de memória para transmitir o saber estabelecido”. Desde nossa perspectiva não cabe ao mestre tão somente transmitir conteúdos, não é a função precípua do professor de filosofia “passar conteúdos”. O que compete então ao professor de filosofia? Deleuze nos diz que:

Nada aprendemos com aquele que nos diz: faça como eu. Nossos únicos mestres são aqueles que nos dizem ‘façam comigo’ e que em vez de nos propor gestos a serem reproduzidos, sabem emitir signos a serem desenvolvidos no heterogêneo.” (1988, p. 54).

Fazer junto... e se essa proposição é válida, o mestre não pode então ser substituído por 'redes de memória', essas podem estar ligadas à informação, mas de modo algum à educação. Educar, proveniente do latino educare, faz referência a uma das deusas dos cultos romanos domésticos, a deusa Educa a que ensinava a comer, não provia o alimento, mas mostrava como dele fazer uso. Ensinar tem sua raiz etimológica no latino insignare, em cuja formação está o 
signo, o sinal, a marca. Ensinar é pois colocar um signo, colocar um exemplo. O professor tem seu lugar na ação coletiva, no fazer junto, suscitando pequenos acontecimentos, rupturas na ordem estabelecida, fraturas no já dado, só possíveis na proximidade do convívio, estimulando o pôr-se em ato o pensamento, gerando junto com seus alunos, mais que apenas levando-lhes um conteúdo a ser absorvido. Graciela Frigerio (2003) assinala que para que se aprender algo é imprescindível uma "relação transferencial" que se estabelece entre o aluno e a alteridade representada pela pessoa do professor. Ouçamos a Freud:

Como psicanalista estou destinado a interessar-me mais pelos processos emocionais que pelos intelectuais, mais pela vida mental do inconsciente que pela consciente. Minha emoção ao encontrar meu velho professor me adverte que antes de tudo devo admitir uma coisa: é difícil dizer se o que mais influência exerceu sobre nós e teve mais importância foi nossa preocupação pelas ciências ou a personalidade de nossos professores” (O. C. XIII, 285).

\section{Referências Bibliográficas}

ABBAGNANO, N. Dicionário de Filosofia. São Paulo: Editora Mestre Jou, 1982.

BADIOU. A. Para uma nova teoria do sujeito.Rio de Janeiro: Relume Dumará,2002.

BUCCI, E.; KEHL, M. R. Videologias. São Paulo: Boitempo, 2004.

CRARY, J. Suspensions of Perception, Attention, Spectacle and ModernCulture, Massachusetts: MIT Press, 2001.

DELEUZE, G. Diferença e Repetição. Rio de Janeiro: Graal, 1988.

FERRAZ, Maria Cristina Franco. Guerra, televisão e superexcitação doscorpos: ensaio de reflexão acerca dos atentados de 11 de setembro de 2001.In: PORTO, Sérgio Dayrell (org.). A incompreensão das diferenças: 11 desetembro em Nova York. Brasília: IESB, 2002.

FREUD, S. Algumas reflexões sobre a psicologia do escolar. In: ObrasCompletas. Vol. XIII, Rio de Janeiro: Imago, 1974.

FRIGERIO, G. “A propósito del maestro ignorante y sus lecciones: testimonio de una relación Números 8/9: Maio/2007 - abril/2008 
transferencial”. In: Educação e Sociedade, v.24, n. 82. Campinas, abril, 2003.

GUATTARI, F. Chaosmos: An ethico-aesthetic paradigm. Bloomington: Indiana University Press, 1995.

JAMESON, F. Pós-modernismo, a lógica cultural do capitalismo tardio. São Paulo: Ed. Ática, 1997.

\footnotetext{
${ }^{\text {i }}$ Este artigo foi apresentado em maio de 2007 no VII Simpósio Sul-Brasileiro sobre o Ensino de Filosofia, na Pontifícia Universidade Católica do Rio Grande do Sul (PUC-RS).

ii Professora de Filosofia do Colégio Pedro II; doutoranda do Programa de pós-graduação em educação da Universidade do Estado do Rio de Janeiro (UERJ) - ingrid.x@terra.com.br.

iii Parecer 38/2006 do Conselho Nacional de Educação (CNE), 11 de agosto de 2006.

iv GUATTARI. F. Chaosmos: An Ethico-Aesthetic Paradigm. Bloomington: Indiana University Press, 1995, p.16-17 “[...] quando assisto televisão, existo em uma interseção 1) de uma fascinação perpétua provocada pela animação luminosa da tela que beira o hipnótico 2) de uma relação de captura pelo conteúdo narrativo do programa, associado ao dar-me conta dos eventos circundantes - água fervendo no fogão, um grito de criança, o telefone...3) de um mundo de fantasmas povoando meus devaneios. Meu sentido de identidade pessoal é puxado em diferentes direções. Como posso manter um relativo sentido de unidade a despeito da diversidade de componentes de subjetivação que me atravessam?”
}

` VIRILIO, P. L'écran du désert (chroniques de la guerre). Paris: Galilée, 1991. P 38-39 apud FERRAZ, M.C.F in, "Guerra, televisão e superexcitação dos corpos: ensaio de reflexão acerca dos atentados de 11 de setembro de 2001”, PORTO, SÉRGIO DAYRELL (org.). A incompreensão das diferenças: 11 de setembro em Nova York. Brasília: IESB, 2002.

${ }^{\text {vi }}$ www.urbi.ubi.pt/000328/edicao/op_cat.html, acessado em 22 de outubro de 2006. 